


\section{VERGILIUS \\ AENEIS BUCH VI}

宙

B. G. TEUBNER STUTTGART UND LEIPZIG 


\title{
P. VERGILIUS MARO AENEIS BUCH VI
}

\author{
ERKLÄRT VON \\ EDUARD NORDEN
}

NEUNTE AUFLAGE

NEUDRUCK

DER DRITTEN AUFLAGE 1927

\section{雭}

B. G. TEUBNER STUTTGART UND LEIPZIG 1995 


\section{O degli altri poeti onore e lume, Vagliami il lungo studio $\theta$ il grande amore Che mi he fatto cercar lo tuo volume. DANTE.}

Die Deutsche Bibliothek - CIP-Einheitsaufnahme

Norden, Eduard:

P. Vergilius Maro, Aeneis Buch VI / erkl. von Eduard Norden.

- Unveränd. Neudr. der 3. Aufl. 1927, 9. Aufl. Stuttgart ; Leipzig : Teubner, 1995

(Sammlung wissenschaftlicher Commentare)

ISBN 3-519-07225-4

NE: Vergilius Maro, Publius: Aeneis

Das Werk einschließlich aller seiner Teile ist urheberrechtlich geschützt. Jede Verwertung außerhalb der engen Grenzen des Urheberrechtsgesetzes ist ohne Zustimmung des Verlages unzulässig und strafbar. Das gilt besonders für Vervielfältigungen, Übersetzungen, Mikroverfilmungen und die Einspeicherung und Verarbeitung in elektronischen Systemen.

(C) B. G. Teubner Stuttgart und Leipzig 1995

Printed in Germany

Druck: Druckhaus Köthen GmbH

Bindung: Verlagsbuchbinderei D. Mikolai, Berlin 
DEM ANDENKEN

\section{FRIEDRICH LEOS}


